\title{
Feasibility of genetic and immunological prediction of Type I diabetes in a population-based birth cohort
}

\author{
A.Kupila ${ }^{1}$, P.Muona ${ }^{1}$, T. Simell ${ }^{1}$, P. Arvilommi ${ }^{1}$, H.Savolainen ${ }^{1}$, A.-M.Hämäläinen ${ }^{3}$, S. Korhonen $^{3}$, T. Kimpimäki ${ }^{4}$, \\ M.Sjöroos ${ }^{2}$, J. Ilonen ${ }^{2}$, M. Knip ${ }^{4}$, O.Simell ${ }^{1}$
}

Juvenile Diabetes Research Foundation Centre for the Prevention of Type I diabetes in Finland:

${ }^{1}$ Department of Paediatrics, University of Turku, Finland

${ }^{2}$ Department of Virology, University of Turku, Finland

${ }^{3}$ Department of Paediatrics, University of Oulu, Oulu, Finland

${ }^{4}$ Department of Paediatrics, University of Tampere Medical School, Tampere, Finland

\section{Abstract}

Aims/hypothesis. Population-wide genetic screening of susceptibility to multifactorial diseases will become relevant as knowledge of the pathogenesis of these diseases increases and preventive interventions are identified.

Methods. Feasibility and acceptance of neonatal genetic screening for Type I (insulin-dependent) diabetes mellitus susceptibility and adherence of the atrisk children to frequent autoantibody follow-up were studied. Screening was offered to all families. The infants with $H L A-D Q B 1$ genotypes $* 02 / * 0302$ and $* 0302 / x(\mathrm{x} * * 02, * 0301, * 0602)$ were invited to autoantibody follow-up. The children who developed signs of $\beta$-cell autoimmunity were invited to a separate prevention trial.

Results. The parents of 31526 babies born between November 1994 and April 1999 (94.4\% of those eligible) agreed to genetic screening. We found that 4651 infants $(14.8 \%)$ had increased genetic risk (2.5 to 15 times that of the general population) for Type I (insulin-dependent) diabetes mellitus, and $80 \%$ of them joined the autoantibody surveillance. At the age of $1,2,3$ and 4 years, 74, 69, 68 and $76 \%$ of the at-risk children, respectively, attended the follow-up. A total of 17 of the 22 children ( $77 \%$ ) who were born during the study period and have developed diabetes carry the risk genotypes we currently use for screening. Conclusions/interpretation. Population-based screening of genetic susceptibility for Type I diabetes, linked with a possibility to participate later in a prevention trial, is highly accepted in Finland and identifies about $75 \%$ of those developing diabetes at an early age. Families adhere well to the frequent measurement of signs of $\beta$-cell autoimmunity in the children at-risk. [Diabetologia (2001) 44: 290-297]

Keywords Autoantibodies, Finland, follow-up studies, HLA-DQ antigens, infant, mass screening, population surveillance, risk assessment.
Progression to multifactorial diseases is determined jointly by genes and environment. A valid approach for the prediction and prevention of such diseases might be to define at birth, or at an early age, the pop-

Received: 13 July 2000 and in revised form: 5 October 2000

Corresponding author: A. Kupila MD, Dept. of Paediatrics, Univ. of Turku, Kiinamyllynkatu 4-8, FIN-20520 Turku, Finland

Abbreviations: DIPP, the Type I Diabetes Prediction and Prevention project; ICA, islet-cell antibodies; IAA, insulin autoantibodies; GADA, antibodies to glutamic acid decarboxylase; IA-2A, antibodies to protein tyrosine phosphatase-like antigen IA-2. ulation at increased genetic risk by analysing the risk genes or risk alleles, the subsequent follow-up of those at risk, and the appropriate implementation of preventive measures at optimum time, if available. The feasibility and acceptance of population-wide genetic tests aimed at an early recognition of the risk of common multifactorial diseases with clinical presentation later in life is not known.

The Type I Diabetes Prediction and Prevention project (DIPP) is an effort to predict and search for means to delay or prevent the disease in a large population-based cohort of children in Finland. The case of Type I diabetes is probably a useful model for the prediction and prevention of chronic, multifactorial 
diseases in the population, as the most prominent susceptibility genes are known and a practical screening methodology has been developed, and the estimation of stepwise increases in disease risk using immunological and metabolic markers is possible during the follow-up of the at-risk subjects. The long, though variable time interval between the appearance of signs of autoimmunity and the clinical disease also allows potential candidate interventions aiming at attenuation of the autoimmune destruction of pancreatic $\beta$-cells to be tested.

In non-obese diabetic (NOD) mice and Bio Breeding $(\mathrm{BB})$ rats, well characterised models of spontaneous autoimmune diabetes, progression to diabetes can be markedly delayed by several immunological and other interventions even when signs of $\beta$-cell autoimmunity are recognised, especially if the insulin secretory capacity of the animal is relatively well preserved [1-3]. Preliminary observations in first-degree relatives of subjects with Type I (insulin-dependent) diabetes mellitus suggest that the disease could be prevented in humans $[4,5]$.

Since only about $10 \%$ of the patients with newlydiagnosed Type I diabetes have an affected first-degree relative, trials based on screening relatives of affected subjects for autoantibodies find only a fraction of the future patients [6,7]. Accordingly, populationbased approaches are needed for strategies aimed at an effective decrease in diabetes incidence in the general population to succeed.

The $H L A-D Q B 1$ genotypes conferring the highest diabetes risk in Finnish children are used as the backbone of the screening in the DIPP project. The genotypes define children with a risk of $8 \%$ (the high-risk children) and of 1.7-2.6\% (the moderate-risk children) for Type I diabetes [8], whereas the average risk for a Finnish child to develop the disease before the age of 15 years is currently $0.7 \%$ [9]. When diabetes-associated autoantibodies appear as the sign of ongoing autoimmunity, the disease risk is expected to have increased substantially $[10,11]$ and the efficacy of intranasally applied insulin is tested as immunomodulatory therapy in disease prevention. This population-based project aims at finding about $50 \%$ of the future patients with Type I diabetes in the population cohort by genetic screening and immunological follow-up. This report outlines the overall protocol of the project, summarises the efficacy data on the genetic screening of the newborn infants and evaluates feasibility and acceptability of prediction of Type I diabetes during the first 4 years of the study.

\section{Subjects and methods}

Study design. The DIPP project runs now in three centres in Finland with a combined annual birth rate of 11000 , representing almost $20 \%$ of all births in Finland. The project began in
Turku in November 1994; Oulu joined the study one year and Tampere three years later. Analysis of genetic susceptibility for Type I diabetes of the newborn infant is proposed to parents in the first days after delivery. The infants at increased genetic risk are then closely followed for signs of diabetes-associated autoimmunity. Infants with severe systemic disease or anomalies are excluded, as are children with both parents of non-Caucasian origin, since the selected $H L A-D Q$ alleles could have a lower predictive value in non-Caucasian populations [12]. In Finland over $99 \%$ of the population is Caucasian.

In practice, a research nurse informs the parents about the DIPP project at the maternity ward, delivers an information brochure and asks for written consent for genetic testing of the cord blood sample drawn at birth together with the routine sample taken for testing of congenital hypothyroidism (Table 1). After 8-12 weeks the families whose baby has been identified as having a risk genotype for Type I diabetes are approached by phone or mail and invited to a counselling visit. The rest are informed by letter. During the visit, a physician informs the family about diabetes in general, the implication of the child's genetic diabetes risk and the DIPP study. Written material on the same topics is also provided. If the parents decide that their child will participate in the autoantibody surveillance programme,written consent is obtained. In Turku, the children are monitored at 3-month intervals until 2 years of age and then twice a year, and in Oulu and Tampere at the ages of 3, 6, 12, 18 and 24 months and then once a year. At each visit, a blood sample is drawn to measure islet-cell antibodies (ICA) [13] and for the storage of serum at $-70^{\circ} \mathrm{C}$. Analgesic lidocaine-prilocaine cream (EMLA, Astra, Sweden) is used before venipuncture, unless parents wish otherwise. If a child seroconverts to ICA positivity, autoantibodies to insulin (IAA) [14], glutamic acid decarboxylase (GADA) [15] and protein tyrosine phosphatase-like antigen IA-2 (IA-2A) [16] are measured in all samples obtained from that child and the follow-up visits are at 3-month intervals thereafter. If the child is 1 year of age or older and has developed autoantibodies, the first-phase insulin response to intravenous glucose is evaluated at 6-12 month intervals. If the parents so decide, the informative $H L A-D Q B 1$ alleles of the siblings of the at-risk newborn baby are also analysed. The siblings with increased genetic risk form a separate cohort in the study. The ethics committees of all participating universities and hospitals have approved the study.

The DIPP project also aims to clarify the pathomechanism of Type I diabetes development and substudies analysing several potentially important factors are included in the protocol.

Genetic screening. The $H L A-D Q B 1$ alleles *02, *0301, *0302, $* 0602$ and $* 0603$ are analysed in all samples, and males positive for $D Q B 1 * 02$ are typed for $D Q A 1$ alleles $* 0201$ and $* 05$ in the Turku cohort. Four drops of cord blood are applied on filter paper (Schleicher \& Schuell, Dassel, Germany) and dried at room temperature. Informative DNA sequences are amplified directly from 3-mm circles which are punched out from the filter paper spots into 96-well PCR plates (Thermowell, Corning Costar, the Netherlands). Defined PCR-amplified gene sequences are hybridised in solution with allele-specific, lanthanide (europium, terbium or samarium) chelate-labelled oligonucleotide probes, and the hybridisation products are detected using time-resolved fluorometry (VICTOR fluorometer, Wallac, Turku, Finland). Details of the assay have been described $[8,17]$.

Carriers of the HLA-DQB1 genotypes *02/*0302 and $* 0302 / x(\mathrm{x} \neq * 02, * 0301$ or $* 0602)$ are selected for follow-up. Children with the genotype $* 02 / * 0302$ are categorised to the high-risk group, and those with the genotypes $* 0302 / x$ to the 
Table 1. Follow-up protocol of the DIPP project

\begin{tabular}{|c|c|c|c|}
\hline Age & Subjects & Event & Measurement \\
\hline Birth & All newborn infants & $\begin{array}{l}\text { Genetic screening } \\
\text { (after informed consent) }\end{array}$ & $\begin{array}{l}\text { Cord blood sample for } H L A-D Q B 1 \text { alleles } \\
\text { for susceptibility to and protection from } \\
\text { Type I diabetes }\end{array}$ \\
\hline \multirow[t]{3}{*}{$\begin{array}{l}3 \text { months, then continuously } \\
\text { at } 3-12 \text { month intervals }\end{array}$} & At-risk children & $\begin{array}{l}\text { Follow-up visits, Research } \\
\text { Nurse (after informed } \\
\text { consent) }\end{array}$ & $\begin{array}{l}\text { Blood samples for ICA measurement (if } \\
\text { positive, IAA, GADA, and IA-2A are also } \\
\text { measured in this and all previous samples) } \\
\text { T-cell responses and enterovirus studies } \\
\text { Growth: weight and height }\end{array}$ \\
\hline & At-risk children & Interview & $\begin{array}{l}\text { Infections, diet, immunisations, medica- } \\
\text { tions, allergies, day care }\end{array}$ \\
\hline & Subcohort of at-risk children & Interview & $\begin{array}{l}\text { Psychological evaluation of stress caused by } \\
\text { genetic screening, ICA follow-up and au- } \\
\text { toantibody seroconversion }\end{array}$ \\
\hline After 12 months & ICA positive eligible children & $\begin{array}{l}\text { Intervention (after } \\
\text { informed consent) }\end{array}$ & $\begin{array}{l}\text { Daily administration of nasal insulin or pla- } \\
\text { cebo }\end{array}$ \\
\hline
\end{tabular}

moderate-risk group. Before May 1997, DQB1 alleles *0602 and $* 0603$ were indistinguishable in the assay. Consequently, children with *0602-3 were classified as low-risk subjects and they were then excluded from the follow-up. Boys born in Tur$\mathrm{ku}$ in 1998 or later with the genotype $D Q B 1 * 02 / y-D Q A 1 * 05 / z$ $(\mathrm{y} \neq * 0301, * 0302, * 0602, * 0603 ; \mathrm{z} \neq * 0201)$ are also observed as a separate cohort.

Intravenous glucose tolerance test. Test is performed according to the ICARUS recommendation [18] on children older than 1 year of age after seroconversion to ICA positivity, and then at 6-12 month intervals.

Nasal insulin prevention trial. Intervention is briefly described to the families before recruitment to the study and details are explained when autoantibodies appear. A written informed consent (the third consent) is obtained from the parents if they want their child to be placed at random on the placebocontrolled, double-blind prevention trial. As part of preventive therapy, a daily nasal administration of human short-acting insulin (Actrapid $100 \mathrm{IU} / \mathrm{mL}$, Novo Nordisk, Gentofte, Denmark) is studied.

Statistical calculations. To calculate the proportion of attendance (Fig. 1) on for example, the 12-month visit, the denominator was the number of all at-risk children who had reached the age of 15 months and the numerator was the number of the children from the same group who were seen at the 12month visit or later. Available samples represent those children from that same group who actually attended 12-month visit and who have sufficient serum sample for autoantibody measurement. The difference between the number of children participating in the follow-up at 12-months and the number of available samples is due to the fact that some children missed that visit and some blood draws were unsuccessful.

\section{Results}

By the end of April 1999, 35274 babies had been born in the three DIPP centres during the genetic screening programme. A one-month nurses' strike in 1995, when recruitment had to be interrupted, led to the exclusion of 430 children (1.2\%). A total of 1447 children $(4.1 \%)$ were excluded due to being non-eligible or due to a missing cord blood sample. The parents of 31526 of the total of 33397 eligible newborn infants $(94.4 \%)$ gave written informed consent for genetic screening. A total of 4651 screened infants $(14.8 \%)$ were found to be at an increased genetic risk for developing Type I diabetes during childhood according to the inclusion criteria adopted in this study. As described in the Methods, the inclusion criteria were modified slightly during the project to increase the sensitivity of the screening (Fig. 2).

A total of 22 children, who were born in the participating hospitals during the study, have developed Type I diabetes (Table 2). Twelve of them $(54.5 \%)$ participated in the follow-up program, families of three at-risk children $(13.6 \%)$ declined participation, and seven $(31.8 \%)$ children were considered to have a low genetic risk at the time of screening and were therefore not offered the follow-up. Two children who were originally excluded from the follow-up group would with the current risk definition be categorised into the moderate risk group (a boy with the $D Q B 1 * 02 / y-D Q A 1 * 05 / z$ genotype and a boy with the $D Q B 1 * 0302 / * 0603$ genotype). The mean age of the at-risk children who have developed diabetes was 1.6 years (range, $0.8-2.9$ years) at the time of diagnosis, and their female to male ratio was 5 to 12 . 


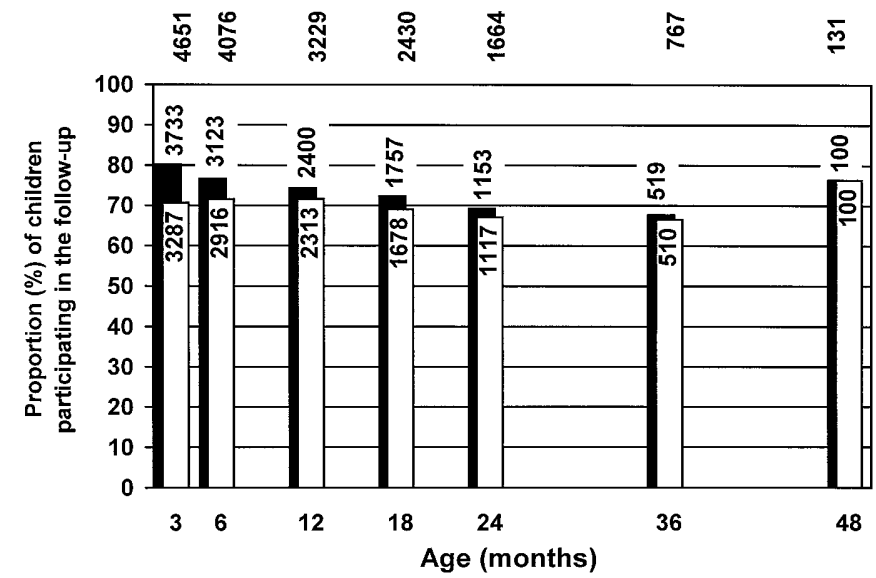

Fig.1. Adherence of the families to the clinical and immunological follow-up. The numbers of the at-risk children who had reached the age "window" for the visit are indicated on the top. Black bars show the proportion and number of the children from that group who participated in the follow-up and the white bars show available samples at visits

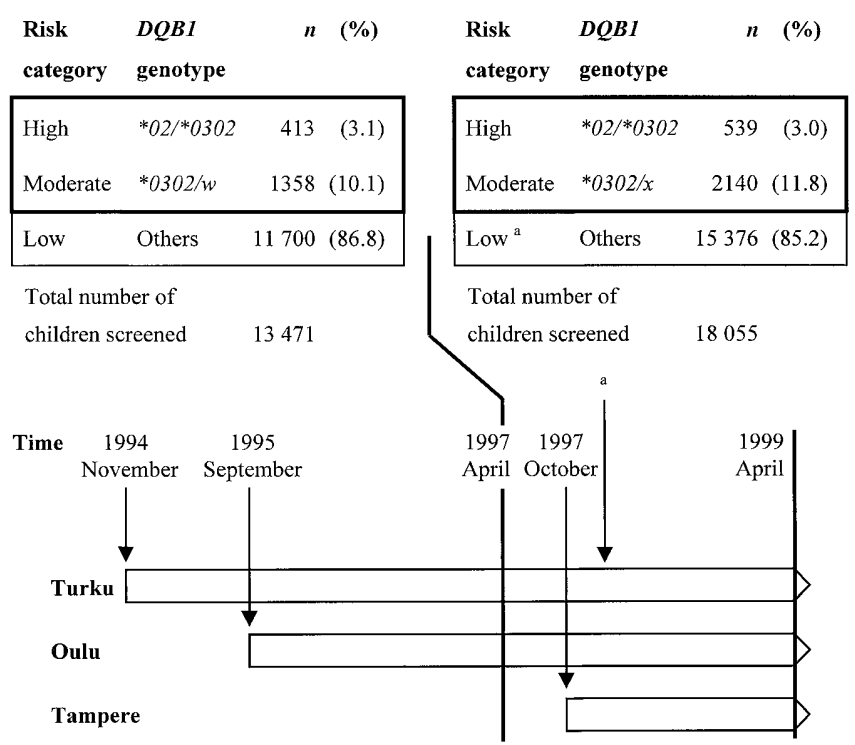

Fig. 2. Different strategies of screening for $H L A-D Q B 1$ associated susceptibility for Type I diabetes during the course of the DIPP project. Children at high or moderate genetic risk are enrolled into follow-up for recognition of diabetes-associated autoimmunity. The accumulated numbers of children in each risk group, the times of changes made in the screening programme and enrolment of children in the three cities (Turku, Oulu and Tampere) are also shown. ${ }^{a}$ Recruitment into the follow-up of a separate cohort of moderate-risk male infants with the $D Q B 1 * 02 / y-D Q A 1 * 05 / z$ genotype started in Turku in January 1998. 201 male newborn infants with this genotype have been identified $(4.7 \%$ of the children born in Turku). For simplicity, these children have been included in the low-risk group in the figure. $\mathrm{w} \neq * 02, * 0301, * 0602-3, \mathrm{x} \neq * 02$, $* 0301$ or $* 0602$
Table 2. Children covered by the genetic screening who developed diabetes

\begin{tabular}{lll}
\hline Genotype $D Q B 1$ & Gender & $\begin{array}{l}\text { Age at diagnosis } \\
\text { (years) }\end{array}$ \\
\hline
\end{tabular}

\begin{tabular}{lll}
\hline Risk children who took part in the autoantibody follow-up: \\
$* 02 / * 0302$ & female & 1.0 \\
$* 02 / * 0302$ & male & 1.2 \\
$* 02 / * 0302$ & male & 1.4 \\
$* 02 / * 0302$ & male & 1.6 \\
$* 02 / * 0302$ & female & 2.1 \\
$* 02 / * 0302$ & male & 2.3 \\
$* 0302 / x$ & female & 1.0 \\
$* 0302 / x$ & female & 1.1 \\
$* 0302 / x$ & female & 1.1 \\
$* 0302 / x$ & male & 2.2 \\
$* 0302 / x$ & male & 2.5 \\
$* 02 / y+D Q A 1 * 05 / z$ & male & 0.8
\end{tabular}

Risk children who did not take part in the autoantibody follow-up: $* 02 / * 0302$

$* 02 /{ }^{*} 0302$

$* 0302 / * 0604$

$* 0302 / * 0603$

male $\quad 1.0$

$3 \quad$ male 1.6

$* 02 / x+D Q A 1 * 05 / z \quad$ male $1.6^{\mathrm{a}}$

Children who were not at increased genetic risk:

$02 / y \quad$ female 2.9

$* 02 / y+D Q A 1 * 05 / z \quad$ female $\quad 1.5$

$* 02 / y+D Q A 1 * 05 / z \quad$ female $\quad 2.9$

other $\quad$ female $\quad 0.8$

$\begin{array}{lll}\text { other } & \text { female } & 1.8\end{array}$

a not defined as a risk genotype at the time of screening (see Methods). $\mathrm{x} \neq * 02, * 0301, * 0602 ; \mathrm{y} \neq * 0301, * 0302, * 0602, * 0603$; $\mathrm{z} \neq * 0201$

All five children who developed diabetes despite a low genetic risk were girls. Their mean age at diagnosis was 2.0 years (range, $0.8-2.9$ years). Thus, the current genetic screening strategy would optimally have found 17 of those $22(77.3 \%)$ screened children who developed diabetes before the age of 3 years.

A total of $80 \%$ of the 4651 families with an at-risk baby gave written informed consent for autoantibody follow-up and attended at least one follow-up visit. Adherence to the follow-up has been high, as 77, 74, $72,69,68$ and $76 \%$ of the at-risk children attended the 6-, 12-, 18-, 24-, 36- and 48-month visits, respectively (Fig. 1). The highest number of drop-outs occurred at the beginning of the follow-up when the parents received the risk information by phone or letter, or immediately after the first counselling visit. Only occasional families discontinue the study after the child had reached the age of 2 years. The time profile of withdrawals remained constant during the study (Fig. 3), as, for example, in the Turku cohort the cumulative proportions of discontinuations were similar in the at-risk children born in 1995, 1996 and 1997 (27.4, 26.1 and $27.7 \%$ had dropped-out by 9 months of age and 32.2, 30.9 and $28.9 \%$ by 18 months of age, respectively). The reasons for drop-outs are not asked routinely, since the families have the right to withdraw from the study at any 


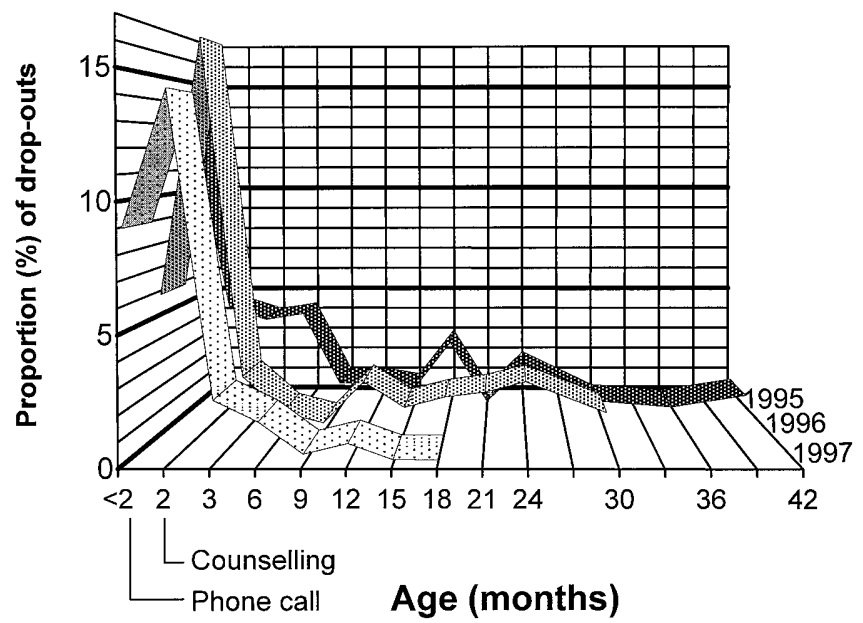

Fig. 3. Timing of the dropouts in the Turku cohort. The absolute proportions of the at-risk children whose families withdrew from the study after receiving risk information by phone or letter, after the first counselling visit, or after scheduled follow-up visits. The cohorts of children born in $1995(n=369)$, $1996(n=463)$, and $1997(n=491)$ are compared

time without an explanation but the reasons are recorded if the parents tell them spontaneously. Reasons most often cited were worries about the blood tests, long distance or travelling difficulties to the clinic, distress in the family other than our study and lack of time. About half of the families gave no reason for their withdrawal. Occasionally parents, who refused the follow-up when they first heard about the risk to their child, joined the trial later.

Altogether, 89 IVGTTs were done on 46 ICA positive children (age range $1.2-4.8$ years; $1-6$ tests per child). Their age was less than 2 years at the time of the test in $26 \%$ of the children. Altogether 9 $(10.1 \%)$ of the tests failed due to an inability to draw sufficient amount of blood. Only 2 of the failed tests were performed on children younger than 2 years.

\section{Discussion}

During the first 4 years of the Type I Diabetes Prediction and Prevention project, genetic susceptibility to Type I diabetes was assessed in a large population cohort of newborn babies in Finland, the country with the highest recorded incidence of childhood diabetes. This study shows that our screening strategy based on selected $H L A-D Q B 1$ genotypes identifies the majority of those children who develop Type I diabetes at least at an early age, i.e., under the age of 3 years. Under optimal circumstances, the current strategy should have identified almost $80 \%$ of these children, but in reality, we were able to observe prospectively about $55 \%$ of the children who have progressed thus far to the disease. The difference in the hypothetical

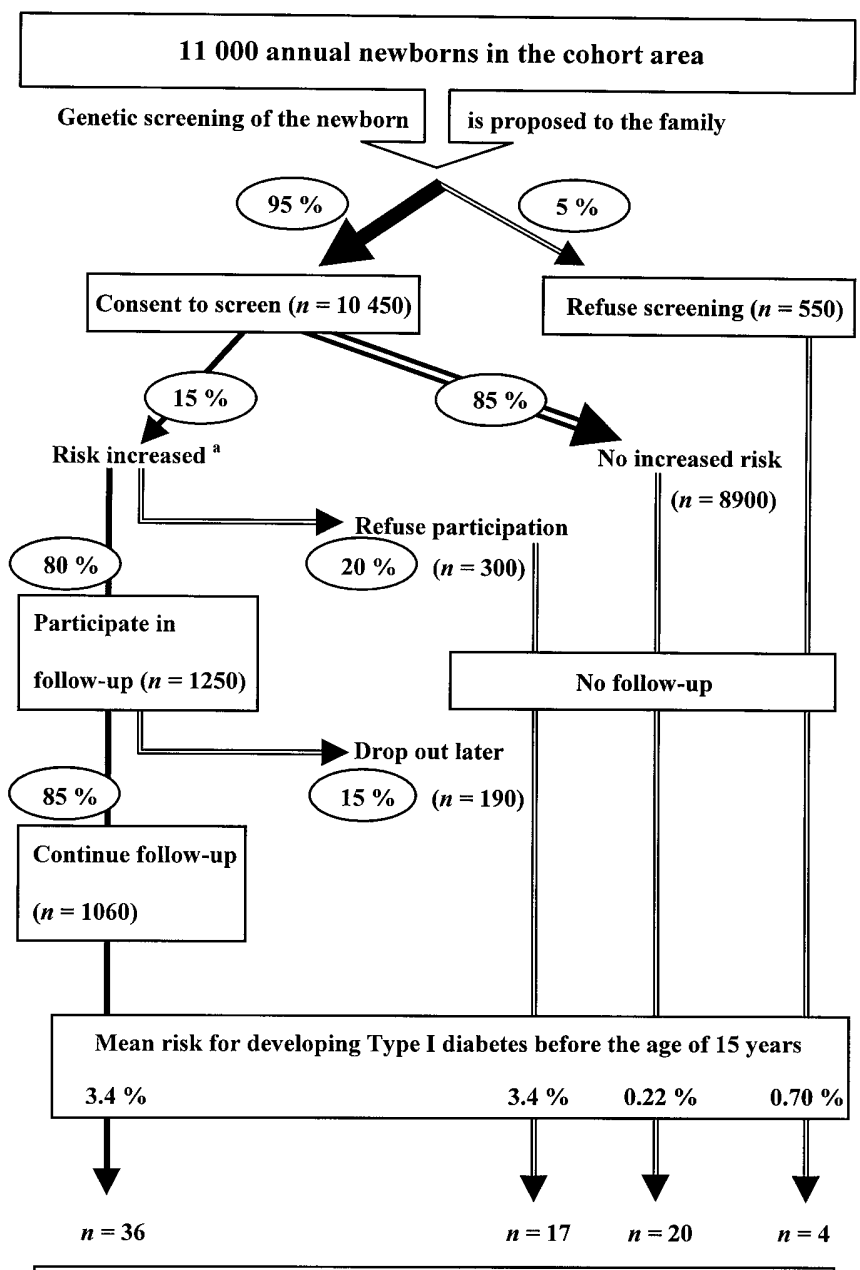

A total of 77 develop Type I diabetes by the age of 15 years

Fig.4. Estimated numbers of children developing Type I diabetes before the age of 15 years in an annual newborn cohort in the DIPP project. Outcome is based partly on the experience gained to date, and partly on estimation of the later compliance. ${ }^{\text {aF }}$ For definition of the risk individuals, see Methods

and real proportions is partly due to refinements in the screening strategy made during the screening programme: two children who with the present criteria would have been included in the follow-up cohort were excluded at the time they were screened. The difference between the theoretical and the real efficacy of the genetic screening is thus likely to decline over time. Withdrawals from the study will, however, prevent full coverage of all future diabetes cases despite improved sensitivity of the screening. The estimated accuracy of the DIPP project in identifying children who develop Type I diabetes under 15 years of age is depicted in Fig. 4. According to our experience so far, the scheme underestimates the proportion of young children found to be at increased risk, but on the other hand, the proportion of withdrawals is likely to increase as the children followed get older. 
The cost of the high sensitivity of the genetic screening is the rather low specificity. Our current screening strategy defines about $15 \%$ of the Finnish population as being at an increased genetic risk for developing Type I diabetes during childhood or adolescence, i.e., carrying a risk at least twice that of the general population. To improve the specificity to sensitivity ratio of the genetic screening, we plan to the use selective decision tree strategy to incorporate the risk information conferred to specific alleles at other $H L A$ loci, as has already been done when $D Q B 1^{*} 02$-positive boys with $D Q A 1 * 05$ were included in the follow-up cohort in Turku. Addition of risk alleles at emerging new susceptibility and protective loci elsewhere in the genome will hopefully improve the efficacy of the genetic prediction further.

Clearly, population-wide genetic screening of newborn infants for genetic risk of Type I diabetes is feasible and widely accepted in Finland. Close to $95 \%$ of the parents consented to genetic screening of their newborn infant(s). The proportion of infants participating has been stable arguing against screening exhaustion.

Genetic screening of a newborn population inevitably raises ethical questions on the justification of such a screening programme: is unnecessary anxiety induced in the parents, does the risk information benefit the subject and is misuse of the accumulating information possible? Our unpublished data, collected by questionnaires at 3 and 12 months after the child's birth, suggest that genetic screening of diabetes susceptibility provokes only transient anxiety among parents. The psychological impact of screening for a multifactorial disease risk, in which the environment plays an important part in the disease development, is likely to differ from the impact of screening for a monogenic disease, in which the genetic component is fully conclusive and not just predisposing. At the moment, voluntary genetic screening for risk genes serves as an irreplaceable tool in research looking for susceptible individuals for intervention trials but the integration of the screening into general health care practice has to wait for effective preventive modalities.

Not only the acceptance of the genetic screening but also the adherence of the families to the frequent immunological follow-up has been excellent in the DIPP study. Most of the dropouts occurred when the child's genetic risk was described to the parents or during the first follow-up year, and only occasionally after the child had been observed for more than 2 years. The high proportion of families participating in the screening and follow-up is probably explained partly by the supportive attitude of the Finnish population towards research but partly too by the well-organised follow-up, pleasant office visits and minimised discomfort of the venipunctures.
The identification of potential future cases of Type I diabetes for prevention trials is laborious and expensive. At the moment, the best surrogate marker of prediabetes is the presence of autoantibodies against $\beta$-cell antigens. In family members of patients with Type I diabetes, multiple diabetes-related autoantibodies are associated with a high risk of diabetes within a few years $[10,19,20]$. In several reports, ICA have been less predictive in cross-sectional studies in children from the general population than in siblings of children with Type I diabetes [11, 21, 22], while ICA predicted diabetes in unselected schoolchildren as efficiently as in high-risk relatives [23]. The predictive value of ICA in the general population could also be enhanced by longitudinal followup, and by selecting only individuals with diabetes-associated $H L A-D Q B 1$ genotypes for immunological follow-up. A combination of genetic screening and immunological approaches is clearly more cost-effective than repeated measurement of autoantibodies in the entire population [24]. Multiple antibody screening would probably be the most sensitive and specific approach for finding subjects who might develop Type 1 diabetes as early as possible, but for economical reasons we chose ICA screening followed by the measurement of other antibodies in children with ICA. Among young Finnish first-degree relatives, ICA is the most sensitive single antibody in prediction of Type 1 diabetes [25].

At the moment, no established therapies to prevent or delay the onset of diabetes exist but safe candidate treatments are available for human trials. We have chosen the time of the appearance of diabetesassociated autoantibodies as the point for offering participation in the prevention trial with intranasally applied human insulin, implied to induce tolerance to insulin, an important $\beta$-cell autoantigen. Endogenous insulin could itself be a central target of the destructive $\mathrm{T}$ lymphocytes attacking $\beta$-cells but the effect might also be mediated via a bystander effect of insulin-specific regulatory cells [26]. Arguments for choosing insulin for the intervention trial included its safety, availability and practicality of application.

Two other extensive longitudinal studies, the German BABY-DIAB study [27] and the DAISY study in the US [28], aim at recognising diabetes-prone subjects at an early age. The BABY-DIAB study observes the development of autoimmunity in children of parents with Type I diabetes and of mothers with gestational diabetes, whereas in the DAISY study the risk subjects for immunological follow-up are identified at birth from the general population by the genetic screening of selected HLA markers. Both studies are designed to throw light on the course of $\beta$-cell directed autoimmunity during early childhood in risk subjects and they do not include any intervention arm. Results from the BABY-DIAB study 
indicate that autoimmunity is initiated very early in life and antibodies to islet antigens usually appear before 5 years of age [27]. The development of diabetesrelated autoimmunity could differ, however, in subjects with or without a family history of diabetes.

Two large-scale prospective, randomised trials (the European Nicotinamide Diabetes Intervention Trial [6] and the Diabetes Prevention Trial - Type 1 Diabetes in the U.S. [7]) currently test preventive therapies on high-risk first-degree relatives of patients with Type I diabetes. Whether the feasibility and outcome data of these studies are directly applicable to the prevention of Type I diabetes in the general population is not clear.

If effective preventive measures against human Type I diabetes are to be identified, then methods to identify accurately the high-risk subjects who would potentially benefit from the prevention are urgently needed. The identification has to be simple to be performed in large population cohorts and the detection of the onset of disease progression has to occur at an early stage to allow time for the intervention. We have shown that population-based screening of risk genetic for Type I diabetes is well accepted in Finland, and that the adherence of the families of the at-risk children to the rather laborious long-term follow-up is high. Our selection of the susceptibility and protective $H L A-D Q B 1$ alleles works well in the prediction of at least early-onset of Type I diabetes, since the majority of the new-onset patients younger than 3 years of age at the time of diagnosis were identified by the risk groups as they are currently defined in the study.

Acknowledgements. This study was supported by Juvenile Diabetes Foundation International (grants 4-1998-274, 197032 and 4-1999-731), Sigrid Juselius Foundation, Academy of Finland, Päivikki and Sakari Sohlberg Foundation, Novo Nordisk Foundation, Jalmari and Rauha Ahokas Foundation, Foundation for Paediatric Research, Finland, Foundation for Diabetes Research, Finland, Signe and Ane Gyllenberg Foundation, and Special Grants for University Hospitals of Turku, Oulu and Tampere. We thank all families participating in the Type I Diabetes Prediction and Prevention project; T. Laurén, M. Karlsson and R. Suominen for genetic screening in practice; P. Asunta, S. Erkkilä, H. Haapanen, R. Hakala, T. Kalliokoski, U. Markkanen, E. Mäntymäki, B. Nurmi, K. Pesonen, H. Pohjola, K. Rasimus, K. Riikonen, R. Sihvo, A. Stenius, A. Suutari, A. Toivonen, M. Törmä, and M. Äikäs for dedicating their time to the best of the study children and families; and the personnel at the Departments of Obstetrics and Gynaecology of the Turku, Oulu and Tampere University Hospitals for their help.

\section{References}

1. Gotfredsen CF, Buschard K, Frandsen EK (1985) Reduction of diabetes incidence of BB Wistar rats by early prophylactic insulin treatment of diabetes-prone animals. Diabetologia 28: 933-935
2. Atkinson MA, Maclaren NK, Luchetta R (1990) Insulitis and diabetes in NOD mice reduced by prophylactic insulin therapy. Diabetes 39: 933-937

3. Bach JF (1994) Insulin-dependent diabetes mellitus as an autoimmune disease. Endocr Rev 15: 516-542

4. Keller RJ, Eisenbarth GS, Jackson RA (1993) Insulin prophylaxis in individuals at high risk of type I diabetes. Lancet 341: 927-928

5. Füchtenbusch M, Rabl W, Grassl B, Bachmann W, Standl E, Ziegler AG (1998) Delay of Type I diabetes in high risk, first degree relatives by parenteral antigen administration: the Schwabing Insulin Prophylaxis Pilot Trial. Diabetologia 41: 536-541

6. Alberti KG (1993) Preventing insulin dependent diabetes mellitus. BMJ 307: 1435-1436

7. DPT-1 Study Group (1995) The Diabetes Prevention TrialType 1 diabetes (DPT-1): implementation of screening and staging of relatives. Transplant Proc 27: 3377-3377

8. Nejentsev S, Sjöroos M, Soukka T et al. (1999) Population based genetic screening for Type 1 diabetes mellitus risk in Finland: Selective genotyping of the markers in the HLADQB1, HLA-DQA1 and HLA-DRB1 loci. Diabetic Med 16: 985-992

9. Tuomilehto J, Karvonen M, Pitkäniemi J et al. (1999) Record-high incidence of Type I (insulin-dependent) diabetes mellitus in Finnish children. The Finnish Childhood Type I Diabetes Registry Group. Diabetologia 42: 655-660

10. Bingley PJ (1996) Interactions of age, islet cell antibodies, insulin autoantibodies, and first-phase insulin response in predicting risk of progression to IDDM in ICA + relatives: the ICARUS data set. Diabetes 45: 1720-1728

11. Lévy-Marchal C, Dubois F, Noël M, Tichet J, Czernichow P (1995) Immunogenetic determinants and prediction of IDDM in French schoolchildren. Diabetes 44: 1029-1032

12. Thorsby E, Rønningen KS (1993) Particular HLA-DQ molecules play a dominant role in determining susceptibility or resistance to type 1 (insulin-dependent) diabetes mellitus. Diabetologia 36: 371-377

13. Karjalainen JK (1990) Islet cell antibodies as predictive markers for IDDM in children with high background incidence of disease. Diabetes 39: 1144-1150

14. Williams AJ, Bingley PJ, Bonifacio E, Palmer JP, Gale EA (1997) A novel micro-assay for insulin autoantibodies. J Autoimmun 10: 473-478

15. Savola K, Sabbah E, Kulmala P, Vähäsalo P, Ilonen J, Knip M (1998) Autoantibodies associated with Type I diabetes mellitus persist after diagnosis in children. Diabetologia 41: 1293-1297

16. Savola K, Bonifacio E, Sabbah E et al. (1998) IA-2 antibodies - a sensitive marker of IDDM with clinical onset in childhood and adolescence. Childhood Diabetes in Finland Study Group. Diabetologia 41: 424-429

17. Sjöroos M, Iitiä A, Ilonen J, Reijonen H, Lövgren T (1995) Triple-label hybridization assay for type-1 diabetes-related HLA alleles. Biotechniques 18: 870-877

18. Bingley PJ, Colman P, Eisenbarth GS et al. (1992) Standardization of IVGTT to predict IDDM. Diabetes Care 15: 1313-1316

19. Verge CF, Gianani R, Kawasaki E et al. (1996) Prediction of type I diabetes in first-degree relatives using a combination of insulin, GAD, and ICA512bdc/IA-2 autoantibodies. Diabetes 45: 926-933

20. Mrena S, Savola K, Kulmala P, Åkerblom HK, Knip M (1999) Staging of preclinical type 1 diabetes in siblings of affected children. Pediatrics 104: 925-930

21. Bingley PJ, Bonifacio E, Williams AJ, Genovese S, Bottazzo GF, Gale EA (1997) Prediction of IDDM in the gen- 
eral population: strategies based on combinations of autoantibody markers. Diabetes 46: 1701-1710

22. Knip M, Karjalainen J, Åkerblom HK (1998) Islet cell antibodies are less predictive of IDDM among unaffected children in the general population than in sibs of children with diabetes. The Childhood Diabetes in Finland Study Group. Diabetes Care 21: 1670-1673

23. Schatz D, Krischer J, Horne G et al. (1994) Islet cell antibodies predict insulin-dependent diabetes in United States school age children as powerfully as in unaffected relatives. J Clin Invest 93: 2403-2407

24. Hahl J, Simell T, Ilonen J, Knip M, Simell O (1998) Costs of predicting IDDM. Diabetologia 41: 79-85

25. Kulmala P, Savola K, Petersen JS et al. (1998) Prediction of insulin-dependent diabetes mellitus in siblings of children with diabetes. A population-based study. The Childhood
Diabetes in Finland Study Group. J Clin Invest 101: 327-336

26. Weiner HL (1997) Oral tolerance: immune mechanisms and treatment of autoimmune diseases. Immunol Today 18: $335-343$

27. Roll U, Christie MR, Füchtenbusch M, Payton MA, Hawkes CJ, Ziegler AG (1996) Perinatal autoimmunity in offspring of diabetic parents. The German Multicenter BABY-DIAB study: detection of humoral immune responses to islet antigens in early childhood. Diabetes 45: 967-973

28. Rewers M, Bugawan TL, Norris JM et al. (1996) Newborn screening for HLA markers associated with IDDM: diabetes autoimmunity study in the young (DAISY). Diabetologia 39: $807-812$ 